\begin{tabular}{|c|c|}
\hline Title & $\begin{array}{l}\text { Anal ysi s of Japanese MT educat i on requi r ement s } \\
\text { by a Needs- Seeds mat rix }\end{array}$ \\
\hline Author(s) & Okut su, S. ; I kawa, Y.; Kameoka, A. \\
\hline Citation & $\begin{array}{l}\text { Proceedi ngs, } 2004 \text { I EEE I nt er nat i onal Engi neer i ng } \\
\text { Nanagement Conf er ence, 1: } 248-252\end{array}$ \\
\hline Issue Date & $2004-10$ \\
\hline Type & Conf er ence Paper \\
\hline Text version & publ i sher \\
\hline URL & ht t p: //hdl . handl e. net /10119/4974 \\
\hline Rights & 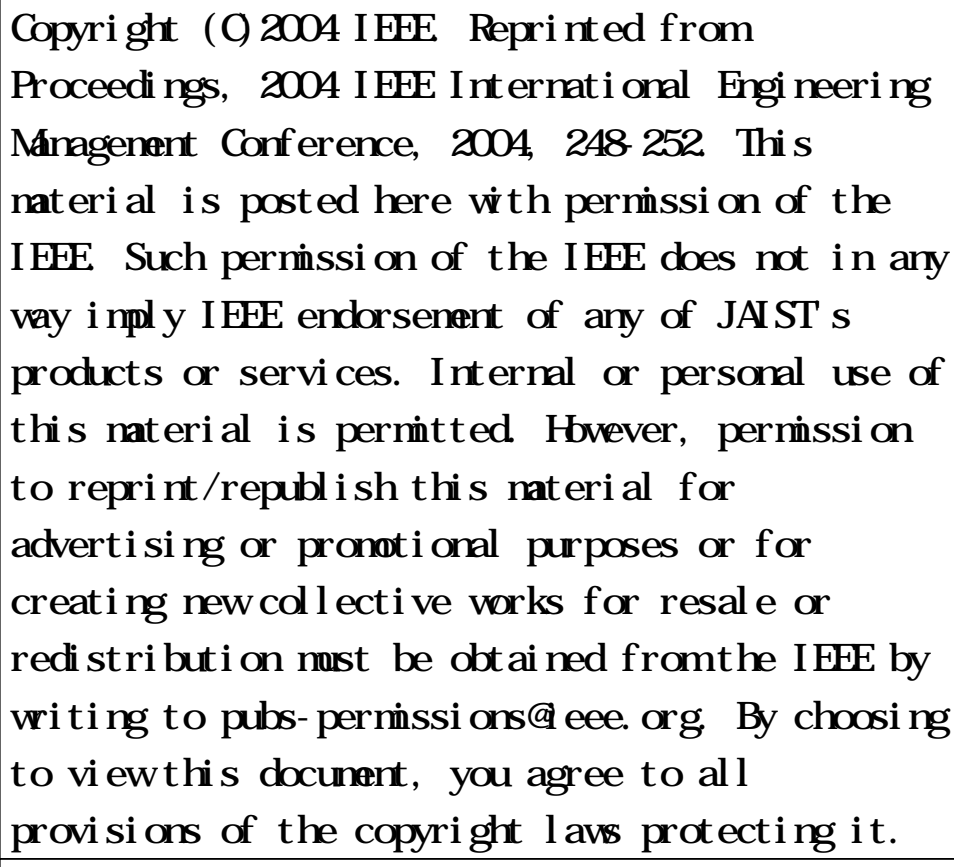 \\
\hline Description & $\begin{array}{l}2004 \text { I EEE I nt er nat i onal Engi neer i ng Nanagement } \\
\text { Conf er ence }\end{array}$ \\
\hline
\end{tabular}

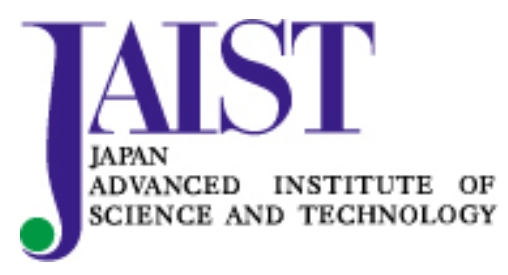




\title{
Analysis of Japanese MOT Education Requirements by a Needs-Seeds Matrix
}

\author{
S. Okutsu, Y. Ikawa and A. Kameoka \\ Japan Advanced Institute of Science and Technology (JAIST), Ishikawa, Japan
}

\begin{abstract}
In recent years, MOT (Management of Technology) has been a hot issue in Japan for surviving severe competition in science and technology research, development and business. In this paper, a tendency of newly developed MOT programs through national project until the end of 2003 is analyzed. This analysis just covers limited number of developed programs that are available to be referred at the time of writing this paper through open source, but still might be useful to consider a direction of future development by showing Needs-Seeds Matrix that was constructed with current seeds (elements of developed programs) and potential needs (social and commercial requirements). It is suggested that this type of analysis is useful and should be conducted on a regular basis to make continuous improvement of MOT programs.
\end{abstract}

Keywords-MOT programs, potential needs, needs-seeds matrix

\section{INTRODUCTION}

In recent years, a large number of Management of Technology (MOT) related educational programs have been established in Japan, by both universities and companies. The Ministry of Economics, Trade and Industry (METI) has been guiding the development of such programs since 2002 and there are now (June 2004) participants of 77 members from industries and 69 from educational organizations [1].

The goal of Japanese MOT (JP-MOT) is to enhance the Japanese technological competitiveness, but the question is, how this can be realized in practice.

In this report, the current situation of JP-MOT programs is presented. The potential needs of JP-MOT are also discussed. This macro approach can be used as a starting point for further investigations.

\section{DEVELOPED PROGRAMS: A RESULT OF NATIONAL PROJECT ON MOT DEVELOPMENT (SEEDS)}

TABLE.1. shows MOT programs developed in the period 2002-2004 financed by METI. According to the report published by METI in April 2004 [2], four types of program were identified ${ }^{1}$ : Technology Oriented Program (TOP), Technology Focused Program (TFP), General Management Program (GMP) and Special Program (SP). TOP is a program that is entirely related to the handling

\footnotetext{
${ }^{1}$ The author sorted all MOT programs based on the METI report by the $\mathrm{KJ}$ method which is used for identifying the structure of listed idea. The purpose of this procedure is to obtain a qualitative implication of the MOT programs.
}

of technology in a firm. TFP is a program that deals with general management elements such as accounting, marketing and strategy in the context of MOT. GMP is a program designed for candidates who study general management in MOT course, but there are no emphases of managing technology. SP is a program that deals with implementation issues of technological topics such as ecology, IT, bio- and nano-technology.

Total number of developed programs that were identified in the report is 136 , but some of them have more than two characteristics as shown in Table I.

TABLE I.

TYPES OF DEVELOPED PROGRAMS

\begin{tabular}{|c|c|c|c|}
\hline \multicolumn{2}{|l|}{ Technology Oriented } & \multicolumn{2}{|c|}{ Technology Focused } \\
\hline RED & 13. & Technology Focused GM & 17 \\
\hline Entrepreneurialship & 3 & Intellectual Property & 13 \\
\hline CTO training & 2 & Strategy & \\
\hline Ethics & 2 & Collaboration & \\
\hline Project Management & 2 & Marketing & \\
\hline Strategy & 2 & Knowledge Manage ment & 3 \\
\hline Techonology Roadmapping & 2 & Evaluation & 2 \\
\hline Trend & 2 & Organization & \\
\hline Acquisition & 1 & Finance & \\
\hline Assimiration & 1 & Business Creation & \\
\hline Control & 1 & Project Management & 1. \\
\hline Core Competence & 1 & Leadership & \\
\hline Evaluation & 1 & Decision Making & \\
\hline Human Resource. & 1. & Human Resource & \\
\hline Operation Mgmt & 1. & Design & \\
\hline Iransfer & 1 & Law & 1 \\
\hline Starndardization & 1 & TOTAL, & 59 \\
\hline TOTAL & 37 & & \\
\hline \multicolumn{2}{|c|}{ Geneneral Management } & \multicolumn{2}{|l|}{ Special Program } \\
\hline Entrepreneurialshlp & 21 & Ecology & 14 \\
\hline Finance & 10 & IT & \\
\hline Accounting & 8 & Bio & \\
\hline Marketing & 8 & Nano & \\
\hline Eusiness Plan & 4 & Digital Engineering & 1 \\
\hline Business \& Market Creation & 4 & Robotlos & 1. \\
\hline Strategy & 4 & Health Servlce & \\
\hline Decision Making & 2 & Agricultural Business & \\
\hline Leadership & 2 & Asian Enterprise. & \\
\hline Knowledge Management & 2 & MOT Education tool & \\
\hline International Mgmt & 2 & \multirow[t]{9}{*}{ TOTAL } & \multirow[t]{9}{*}{38} \\
\hline MEA & 1 & & \\
\hline Human Resource & 1 & & \\
\hline Dynamic Management & 1 & & \\
\hline Motivation & 1 & & \\
\hline Control & 1 & & \\
\hline Negotiation & 1 & & \\
\hline Economics & 1 & & \\
\hline TOTAL & 74 & & \\
\hline
\end{tabular}

From Table I, the following observations can be pointed out:

- Whether focusing on technology or its applications, Entrepreneurship seems to be a central topic in JPMOT. 
- Innovation is the main interest in TFP; it has to be studied not only from the technological perspective but also from the commercial perspective.

- R\&D management is the major topic of TOP, but other programs for managing technology have not been well developed yet. There are less TOP programs than TFP and GMP programs.

- Most of programs in SP are focused on high technology and its use. Especially ecology seems to be a main interest at the moment.

- Elements of general management are taught as background knowledge for MOT, especially finance, accounting and marketing.

Fig. 1 shows target candidates/trainees for the MOT programs. The original data was taken from the report by METI [2].

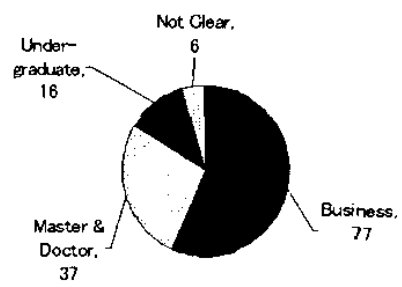

Fig. 1. Target candidate/traintees $(N=136)$

Majority of MOT programs are for business people $(57 \%)$, part of which are handled within MBA courses. Other MOT programs are for academic students (mainly natural sciences and engineering students without business experience), being only $39 \%$ of total MOT programs.

In the US, it was mostly engineering schools that started offering MOT programs [3] [4]. As time went on well into the 90 's, business schools followed this effort to introduce MOT related courses or programs, which were designed on the basis of their MBA programs [5]. Considering the fact that there have been a small number of Japanese MBA programs available, it might be effective and efficient to have national project that accelerates the development and implementation of MOT programs.

There are some claims about appropriate timing and contents of MOT education for academic students who major in natural science or technology [6] [7]. Whether it starts from master or doctoral level, a main goal of the MOT education for them is enhancing entrepreneurship with understanding of basic management framework in the context of technology related business. According to the claim and referring to the history of US-MOT, not only the course for businessperson but also for academics has a big potential.

JP-MOT is expected to be enforced for practical use with further development of R\&D management, aiming at innovation and enhancing entrepreneurship both for business people as well as for academic students.

\section{Potential NEeds: \\ HOW CAN JP-MOT BE UNIQUE AND EFFECTIVE?}

In this chapter, potential needs of Japanese MOT are overviewed from several perspectives: "Weakness \& Strength of international competitiveness", "Relation between company and individual" and "A potential MOT related activities in current company practice".

\section{A. Weakness \& Strength of International competitiveness}

It was revealed that there were needs to develop management competitiveness by the world competitiveness survey carried out by IMD in 2003 . In the report, it was shown that the Japanese management competitiveness was ranked No. 20 out of 30 advanced countries and could not make the most of infrastructures and a big amount of expenditure for R\&D that was No.1 to the contrary[8]. If this unbalance is solved, Japan might be possible to be more competitive with offering even further innovative products and services. As discussed above, the total managerial international competitiveness has still much room to grow. On the other hand, high quality of employee training, high productivity of laboratory members, and retaining skilled labor are positive points [8]. But the ability to invest $\mathrm{R} \& \mathrm{D}$ effectively with regard to quantity of expenditure is often questioned and claimed as a matter that has to be improved.

According to a survey carried by IMD in 2001 involving 49 countries $[9]^{2}$, major managerial weaknesses related to MOT practice were (1) entrepreneurship, both individual and corporate venture, (2) human resource, (3) dynamic marketing culture, (4) financial skill and infrastructure and (5) competent international management.

Regarding the weakness (2), a scale of MOT human resource will strengthen Japan's national competitiveness since "Manufacturing" is a core part $(17.8 \%, 11$ million people) of the total Japanese work force. While there are 12 thousand MOT graduates per year in the US, there are only thousand of graduates per year produced in Japan. METI considers that this number should be raised to be at least 10 thousand for pursuing the same quality level of MOT as that of the US, taking into account the differences and similarities of industrial structure and GDP of the both countries [1].

\section{B. Company and individuals}

The uniqueness of the Japanese management approach has been studied positively both internationally and domestically. The organizational structure is considered more 'organic' [10], and therefore employees are required to use a holistic approach and to make a contribution to

\footnotetext{
${ }^{2}$ The report in 2001 was selected to see the situation
} when the national project has launched in 2002. 
his/her organization [11]. Also unique features of Japanese companies are life-time employment and seniority dependent promotion.

Although recent lengthy downturn of Japanese economy affected this tradition to some extent, example of which is a wide range of restructuring, it is amazing to point out that the average duration of working years has been increasing as shown in Fig. 2 .

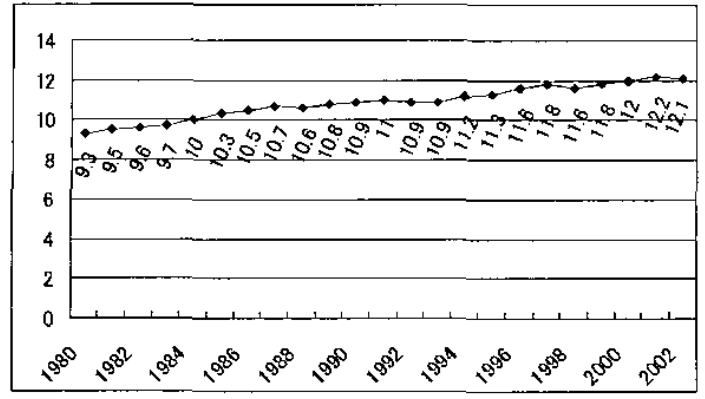

Fig.2. Average working years in one company in Japan Source: Ministry of Health, Labor and Welfare (2003)

Considering this general tendency, potential MOT graduates are likely to continue working in the same organization during and after their MOT education. This raises the question of how to make full use of the human resources in company practice. Learning from best practices in other countries, one alternative may be offering education programs in a corporate university. At least collaboration between companies and educational organizations should be considered.

Fig. 3 shows results of a questionnaire aimed at investigation of potential needs of MOT programs. It was conducted at GATIC (Global Advanced Technology and Innovation Consortium) in October 2003, which was initiated and officially launched in September 2002 by ETH Zurich (Europe), North Western University Kellogg Business School (the US) and JAIST (Japan) [12]. This figure shows potential needs for case development and an opportunity to simulate applicability of learned knowledge and skill during the course.

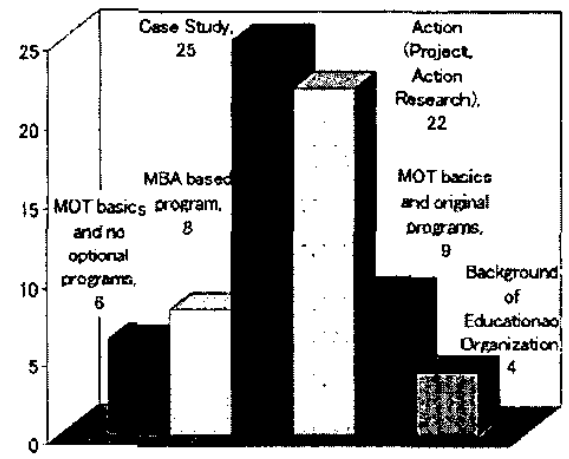

Fig.3. Request for MOT program $(\mathrm{N}=45)$
From the survey of the same source of Table I, method of the program was identified; such as using case or having project or action research. 22 out of 136 programs emphasize case development during the project for the purpose of education, and 3 are developed as action programs.

Though the survey (Table1 and Fig.1) covers only programs developed during the project and a part of a MOT courses held by each educational organization, additional cases should be available to consider further potential needs.

A hidden barrier for the development seems to be the facts that companies are afraid of confidentiality and that educational organization cannot convince them by pointing out the potential benefit. This should be considered to develop JP-MOT programs further.

\section{Potential MOT oriented activities in current company practice}

Among many features of MOT, a key factor of success is a high quality of interaction between technological and commercial perspective [13] [14]. For active interaction in company, it is required to communicate not only within similar sections but also across the organization. In this regard, many approaches have been created.

Knowledge Science (KS) has introduced many cases in Japan that result in success in dealing with technological knowledge in the context of company management activities [15]. It shows that Japanese companies have been practicing MOT related activities. Not only R\&D but also knowledge related activity has been a major concern in Japan: e.g. QC and Kanban (just-in-time method). The MOT contribution will lie in systemic redesign of current company practice and possible challenge of new MOT related activities if necessarily.

\section{HOW TO MATCH SEEDS AND POTENTIAL NEEDS?}

One of the useful methods to see the matching between seeds and needs is 'Needs-Seeds Matrix' (N-S Matrix) approach that has been well studied since early 80's [16]. It might be worth to note the development of programs on the same chart, to revise the matrix continuously to recognize current situation and to accomplish it. It is also possible to expand the matrix (customization) if program providers achieve unique programs and use it for their own organization. Again this tendency check just focuses on limited programs that were developed during the national project until the end of 2003 , in other words, this survey covers only a part of whole seeds (programs) that will be offered to MOT students at each educational organizations.

Current seeds and potential needs are summarized in TABLE II with reference to previous chapters, explaining contents and references / source of each categories. "Reference/Source" clarifies where contents, references and detailed information of national competitiveness are explained. Numbers (x/49) means, "Japan has Xth 
competitiveness out of 49 countries" in the report by IMD

[9].

TABLE II.

EXPLANATION OF EACH CATEGORY IN N-S MATRIX

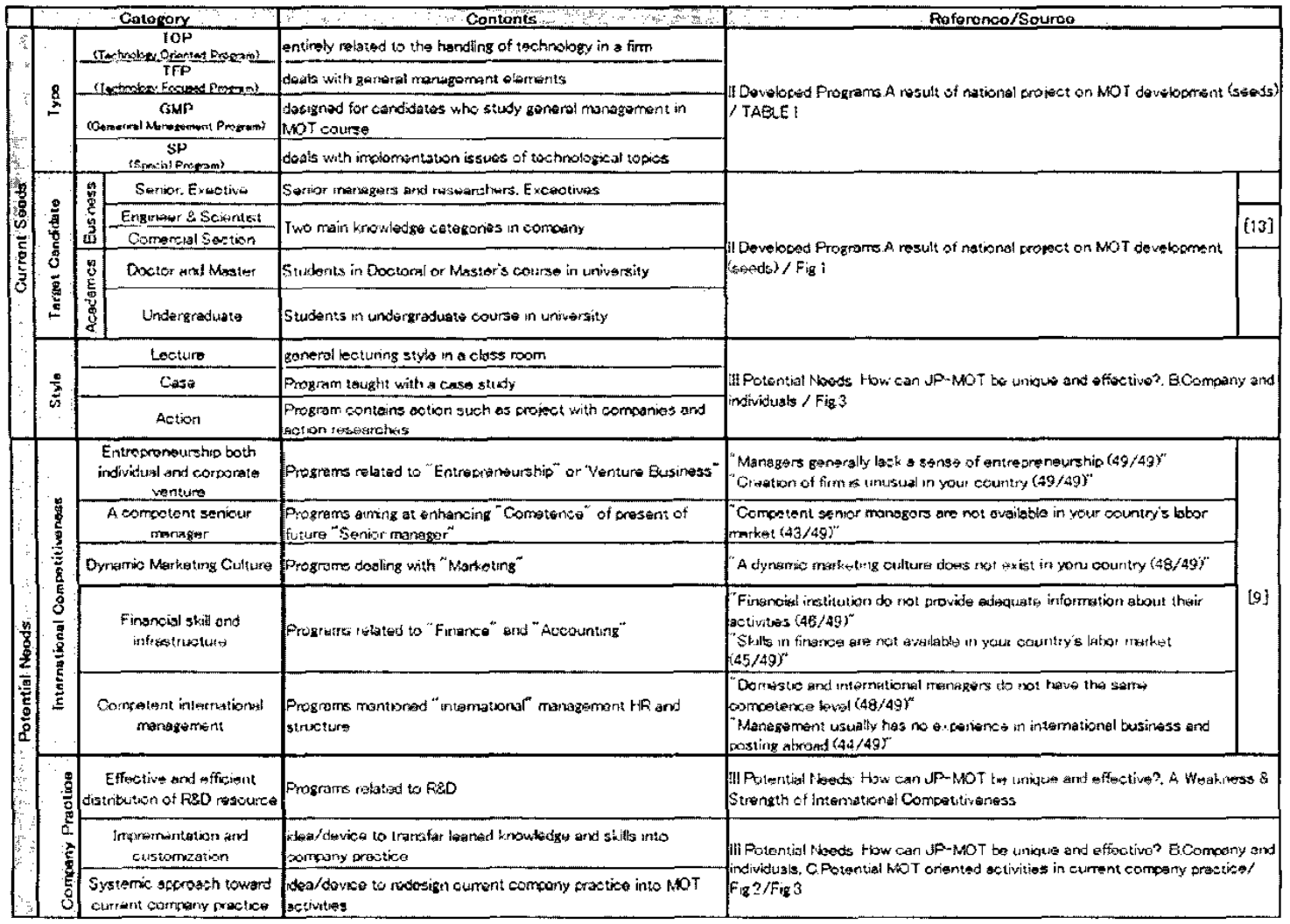

TABLE III.

N-S MATRIX OF CURRENT JP-MOT

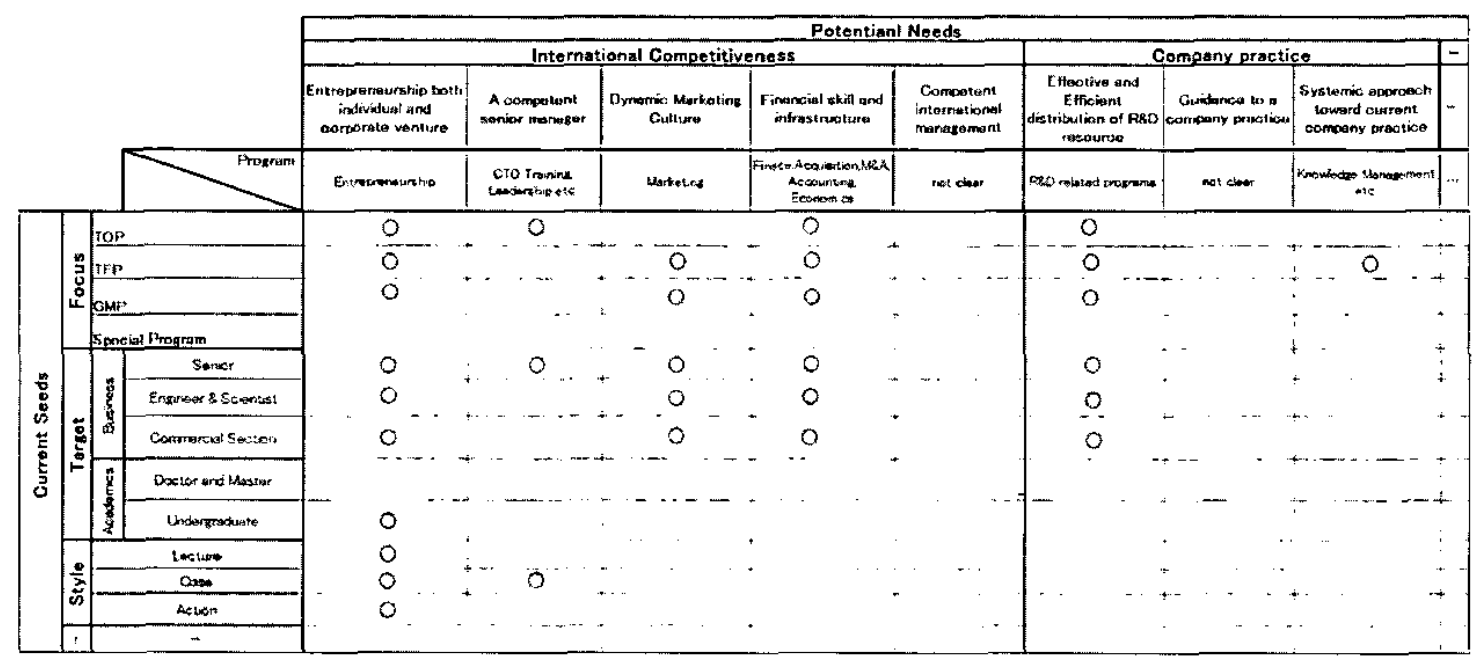


TABLE III is the N-S matrix that describes whether seeds meet needs according to the elements of TABLE II. If there were seeds that should fulfill needs through reading carefully the report [2], a single circle was described. A level of fulfillment was not checked because of the limited data, but simply checked the existence of seed with regards to programs that are aimed at and/or useful for the needs. Empty boxes mean that there were no matches, or the case where seeds were not clear to fulfill the needs.

According to the N-S matrix, MOT programs developed in recent years in Japan seem to cover some part of potential needs, however they seem to weakly focus on other issues, implying that these programs are only accomplishing a part of initially designed MOT courses. It is also assumed that some methods should be considered so that taught knowledge and skills can be transferred into company practice. This can be realized only after well understanding an appropriate bridge between education and business, otherwise company investment toward MOT education or individual effort cannot have productive results. Also cases and action programs are useful for course graduates to turn these explicit knowledge and skills to tacit level, which makes it possible to apply MOT approach flexibly in the context of practice in their own company. This can be enhanced not only by educational organizations but also by companies, as cases and action programs for MOT education will be accomplished by their strong contribution, understanding and cooperation.

For a further MOT enhancement, educational organizations are required first to well explain following three key questions: "Why MOT is effective?" "How company can apply it?" and "What kind of MOT knowledge and skills should be introduced and what is in current practice?" Educational organizations should identify their specific uniqueness and main target candidates/trainees. Some seem to have already targeted and the contents are displayed for this purpose. But most of educational organizations seem to develop their own programs by trial and error, which could make companies confused to understand the effectiveness of MOT. The N$\mathrm{S}$ matrix of MOT education proposed in this paper might be able to help educational organizations as one of the possible guidelines to design their own programs and courses.

It is suggested that this type of survey should be conducted on a regular basis with improved accuracy so that it can contribute to help build better, effective and efficient MOT programs.

\section{CONCLUSION}

Continuous observation of the program development will be necessary, both for JP-MOT as a whole as well as for each educational organization to propose effective and efficient MOT courses. The proposed N-S matrix might help control the gap between planed and developed programs by confirming the fulfillment of potential needs so that the program can be more useful in practice.

This survey covers programs that the author could obtain the information through the public report. Therefore further study must be conducted to fully evaluate the whole picture of the JP-MOT programs. Although such limitation exists in the survey and analysis of this report, it can be pointed out that there are challenges to improve JP-MOT. Also a method to implement knowledge and skills of MOT is still under discussion in spite that each education programs might be developed by their own as temporary alternatives.

\section{ACKNOWLEDGMENT}

The authors are very grateful to Professor Kondou at Japan Advanced Institute of Science and Technology (JAIST) for his valuable suggestions and discussions throughout this study,

\section{REFERENCES}

[1] Ministry of Economy, Trade and Industry, Academia Industry Cooperation Promotion Division, "A Guide to MOT in Japan", Ministry of Economy Trade \& Industry, 2003.

[2] Ministry of Economy, Trade and Industry, Academia Industry Cooperation Promotion Division, "A Report of MOT program development (in Japanese) ", Ministry of Economy, Trade \& Industry, April 23, 2004.

[3] D.F.Kocaoglu, "Research and education characteristics on the engineering management discipline", IEEE Transactions on Engineering Management, vol.37, no.3, pp.122-176, 1990

[4] D.F.Kocaoglu, "Technology Management: Educational Trends", IEEE Transaction on Engineering Management, November New York, 1994.

[5] S.Nambisan, D.Wilemon, "A global study of graduate management of technology programs", Technovation, vol.23, pp.942-962, 2003.

[6] K.Miyazaki, "Perspectives and tasks on MOT education (in Japanese)", in Proc. $17^{\text {th }}$ Conf. The Japan Society for Science Policy and Research management, November 7-8 Tokyo, pp.319-322, 2003.

[7] H.Tschirky, "On the path of the Enterprise Science?".Swiss Federal Institute of Technology (ETH), 2000.

[8] IMD, "The World Competitive Yearbook 2003", IMD, 2003

[9] IMD, "The World Competitive Yearbook 2001", IMD, 2001

[10] T.Kagano, I.Nonaka, K.Sakakibara, A.Okuura, " Comparison of management between Japan and the US (in Japanese), Nihon Keizai Shimbun Inc., 1983.

[11] T.Burns, G.M.Stalker, "The Management of Innovation", Tavistock Publications, 1961

[12] Japan Advanced Institute of Science and Technology (JAIST), "JAIST's MOT:International collaboration" [Online]

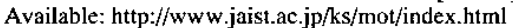

[13] R.Phaal, J.P.C.Farrukh, R.D.Probert, "A framework for supporting the management of technological knowledge", Int.J.Technology Management, vol.27, no.1, pp.1-15, 2004.

[14] E.R.Cole, "Evolution on MOT as Seen through the Experiences of US Berkeley's MTO Program (in Japanese)" Hitotsubashi Business Review, vol.51, no.4, pp. 28-40, Spring, 2004.

[15] I.Nonaka, "The Knowledge-creating Company", Harvard Business Review, Nov-Dec, pp.96-104, 1991.

[16] S.Kondou, "A method of searching a new product and business by Technology Matrix (in Japanese)", Japan Management Association (JMA), 1981 